\title{
ERCP in Management of Common Bile Duct Stones in Children: Safety and Efficacy
}

\author{
Khalid Safwat $^{1}$, Khalid Abd EL-Aziz ${ }^{1}$, Hany Fawezy ${ }^{2}$, Ahmed Yousef ${ }^{1}$ \\ ${ }^{1}$ General Surgery Department, Faculty of Medicine, Zagazig University, Egypt \\ ${ }^{2}$ Pediatrics Department, Faculty of Medicine, Zagazig University, Egypt
}

Corresponding Author Ahmed Yousef

\section{E mail:}

ahmadattia85@yahoo.c om

Key words: Endoscopic retrograde cholangiopancreatogra phy (ERCP); choledocholithiasis; Common bile duct; Children.
Background and study aim: Choledocholithiasis due to common bile duct (CBD) stones is a critical condition in children. The aim of this study was to evaluate the efficacy and safety of endoscopic retrograde cholangiopancreatography (ERCP) in management of CBD stones in children. Patients and methods: Twenty five children suffering from obstructive jaundice were diagnosed and selected after completion of full laboratory and radiological investigations in the period from June 2010 till December 2013 and were admitted to the Surgery Department Zagazig University Hospitals, Egypt. Patients were classified into 2 age groups below and above 6 years to decide the diameter of ERCP scope and the stents used in the procedure. Group A; 0-6 years were 12 patients and Group B; 6-15 years were 13 patients.

Results: ERCP was adequate in helping to predict biliary ductal stones and removal

\section{INTRODUCTION}

Although still rare pediatric calcular obstructive jaundice appears to have been on the rise since the early 1970 s [1]. The causes of this increase are multifactorial and include an improved ability to detect gallstones as well as an actual increased incidence [1,2]. Endoscopic retrograde cholangiopancreatoraphy (ERCP) use in children, has been limited by technical difficulties, low incidence of pancreaticobiliary diseases and lack of knowledge of ERCP by pediatric surgeons and pediatricians [3]. ERCP provides a good definition of the extrahepatic of them in all patients with no reported diagnostic or therapeutic failure. The stent placement was indicated in 21 of the 25 (84\%) children, the other 4 children $(16 \%)$ just sludge was cleared using basket forceps without the need for stent insertion. Two to three weeks later laparoscopic cholecystectomy was successfully performed to all indicated children with removal of the stent after 2 to 3 weeks. There rate of ERCP complications was 12\% (3 cases), one case reported mild pancreatitis and 2 cases reported mild cholagnitis.

Conclusion: The encouraging results of this study with very minimal insignificant complications of ERCP (safety) and good results of ERCP in treatment of CBD stones in children (efficacy) recommend that children with choledocholithiasis due to CBD stone or sludge should be treated by endoscopic CBD stone or sludge removal.

and intrahepatic bile ducts, its most important role is to define usual extrahepatic biliary obstruction and in the diagnosis of sclerosing cholangitis. It also has a role in detecting stones in the CBD. It is also useful in the diagnosis of bile duct patency and thus excluding atresia in cholestatic infants [4]. Therapeutic ERCP reduces the need for surgery and preoperative ERCP provides surgeons with a "Road map" when surgery is required. Success in neonates has also been reported [5]. The aim of this study was to evaluate the efficacy and safety of ERCP in management of CBD stones in children. 


\section{PATIENTS AND METHODS}

This study was conducted between June 2010 and December 2013 at the endoscopy unit, Surgery Department Zagazig University Hospitals, Egypt, and included 25 children with cholestasis due to CBD stones. Patients were referred by the out patient clinic of Pediatric Gastroenterology unit and General Surgery Department Zagazig University Hospitals, they were 11 females and 14 males. Patients were classified into 2 groups according to the age below and above 6 years to decide the diameter of ERCP scope and the stents used. Group (A) 0-6 years; were 12 patients, Group (B) above 6 to 15years; were 13 patients (Table 1). All of them had been diagnosed to have cholestasis due to CBD stones and diagnosis was based on clinical, biochemical and ultrasonic evidence. Their medical records were reviewed and the following information were obtained: age, sex, clinical presentation, investigations and abdominal ultrasound results. All the 25 children were subjected to ERCP (using Pentax 402 ED3485T or Olympus JIF T20 side viewing duodenoscope) under general anesthesia in the operative room using the $\mathrm{C}$-arm (TCA4PLUS) for biliary visulitzation. Of them 23 children were proposed for elective laparoscopic cholecystectomy (LC) within two to three weeks after ERCP. Two to three weeks after LC stent removal under deep sedation (midazolam, ketamine and fentanyl) in the operative room was performed. A detailed informed written consent was obtained from the parents or guardian of all children. This study was approved by our Institutional Review Board.

\section{Statistical Analysis:}

Analysis of the data was carried out using the SPSS (version 12, Chicago, Illinois, USA) software. Data were expressed as number, percentage and mean \pm standard deviation. Comparison between the mean values was performed using the Student's t-test. P values lower than 0.05 was considered statistically significant.

\section{RESULTS}

The study included 25 pediatric patients with age ranged from 2.3 to 13 years (mean age of $6.76 \pm$ 3.9 years). There was no statistical significance between both groups regarding the age and sex (Table 1). All patients presented with manifestations of cholestasis including jaundice, dark urine and pale stools associated with abdominal colic and fever up to $39^{\circ} \mathrm{C}$ (Table 2).

Table (1): Age groups in relation to sex distribution of the studied cases

\begin{tabular}{|l|c|c|c|c|c|c|}
\hline \multirow{3}{*}{ Sex } & \multicolumn{3}{|c|}{\begin{tabular}{c} 
Age groups \\
\cline { 2 - 7 }
\end{tabular}} & \multicolumn{2}{|c|}{$\begin{array}{c}\text { Group A } \\
(\mathbf{n = 1 2})\end{array}$} & \multicolumn{2}{c|}{ Toup B } \\
\cline { 2 - 7 } & No & \% & No & \% & No & \% \\
\hline Male & 7 & 28 & 7 & 28 & 14 & 56 \\
\hline Female & 5 & 20 & 6 & 24 & 11 & 44 \\
\hline Total & 12 & 48 & 13 & 52 & 25 & 100 \\
\hline
\end{tabular}

$\mathrm{P}$ value $=0.22(\mathrm{NS})$

Table (2): Presenting symptoms among the studied cases

\begin{tabular}{|l|c|c|}
\hline & No & \% \\
\hline Abdominal colic & 25 & 100 \\
\hline Vomiting and fever & 25 & 100 \\
\hline Color of urine (dark) & 25 & 100 \\
\hline Color of stool (pale) & 25 & 100 \\
\hline Jaundice & 25 & 100 \\
\hline
\end{tabular}


Regarding the ultrasound findings (Table 3), 18 patients $(72 \%)$ with calcular obstructive jaundice [11 in group B and 7 in group A]. In six patients (24\%) ultrasound diagnosed as obstructive jaundice due to thick bile (Inspissated bile syndrome, Mucovicidosis) [2 in group B and 4 in group A].
Dilated intrahepatic biliary radicles (IHBR) reported in 7 patients (28\%), [3 patients in group A, 4 patients in group B]. One patient in group A (4\%) had in addition parasitic worm (Fasciola) obstructing the CBD.

Table (3): Interpretation of the main ultrasound findings in the studied cases

\begin{tabular}{|c|c|c|c|}
\hline \multirow{2}{*}{ Item } & \multicolumn{2}{|c|}{ Age group } & \multirow{2}{*}{$\begin{array}{c}\text { Total } \\
(\mathbf{n}=\mathbf{2 5})\end{array}$} \\
\hline & Group A & Group B & \\
\hline CBD stones (Choledocholithiasis) & 7 & 11 & 18 \\
\hline Obstructive jaundice by thick bile & 4 & 2 & 6 \\
\hline Dilated IHBR & 3 & 4 & 7 \\
\hline Obstructive jaundice by worm & 1 & - & \\
\hline P value & \multicolumn{2}{|c|}{$0.01(\mathbf{S})$} & \\
\hline
\end{tabular}

The final diagnosis in relation to the sex showed that there was statistical significance between males and females regarding the CBD stones and the inspissated bile syndrome, one male child in group A was diagnosed as obstructive jaundice by parasitic worm (Table 4).

Table (4): Final diagnosis of different age groups in relation to sex distribution of studied cases

\begin{tabular}{|c|c|c|c|c|}
\hline \multirow[b]{2}{*}{ Sex } & \multirow[b]{2}{*}{ Final diagnosis } & \multicolumn{2}{|c|}{ Age groups } & \multirow[b]{2}{*}{ Total } \\
\hline & & $\begin{array}{c}\text { Group A } \\
(n=12)\end{array}$ & $\begin{array}{c}\text { Group B } \\
(\mathbf{n}=13)\end{array}$ & \\
\hline \multirow{3}{*}{$\begin{array}{l}\text { Female } \\
(n=11)\end{array}$} & Calcular obstructive jaundice & 4 & 5 & 9 \\
\hline & Inspissated bile syndrome & 1 & 1 & 2 \\
\hline & Obstructive jaundice with worm & 0 & 0 & 0 \\
\hline \multicolumn{2}{|r|}{ P value } & \multicolumn{2}{|c|}{$0.002(\mathrm{~S})$} & \\
\hline \multirow{3}{*}{$\begin{array}{c}\text { Male } \\
(n=14)\end{array}$} & Calcular obstructive jaundice & 4 & 6 & 10 \\
\hline & Inspissated bile syndrome & 2 & 1 & 3 \\
\hline & Obstructive jaundice with worm & 1 & 0 & 1 \\
\hline & P value & \multicolumn{2}{|c|}{$0.045(S)$} & \\
\hline
\end{tabular}

The CBD cannulation was successful in all patients (100\%). Diagnostic ERCP for cholestasis of obscure etiology was performed in a total of 8 patients (32\%), 4 patients in group A (33.3\%) and 4 patients in group B (33.3\%), while therapeutic ERCP was done in 17 patients $(68 \%)$ [8 patients in group A (32\%), 9 patients in group B (36\%)] (Table 5).

Table (5): Type of ERCP performed in different age groups of the cases

\begin{tabular}{|c|c|c|c|c|c|c|}
\hline \multirow{2}{*}{ Item } & \multicolumn{3}{|c|}{ Age group } & \multicolumn{2}{c|}{ Total } \\
\cline { 2 - 7 } & \multicolumn{2}{|c|}{ Group A } & \multicolumn{2}{|c|}{ Group B } & \multicolumn{2}{c|}{} \\
\cline { 2 - 7 } & No & $\mathbf{\%}$ & No & $\mathbf{\%}$ & No & \% \\
\hline Diagnostic for Cholestasis of obscure etiology & 4 & & 4 & & 8 & 32 \\
\hline Therapeutic in Cholestasis of known etiology & 8 & & 9 & & 17 & 68 \\
\hline Total & 12 & & 13 & & 25 & 100 \\
\hline
\end{tabular}


Findings during ERCP in the studied patients are shown in Table 6. CBD stones were found in 19 child, while biliary parasite (Fasciola) was extracted in one male child in group A. Six cases were diagnosed with mucovicidosis.

Table (6): ERCP diagnosis in the studied patients

\begin{tabular}{|l|c|c|c|c|}
\hline \multirow{2}{*}{ Item } & \multicolumn{2}{|c|}{ Age group } & \multicolumn{2}{c|}{ Total } \\
\cline { 2 - 5 } & Group A & Group B & \multicolumn{2}{c|}{} \\
\cline { 2 - 5 } & No & No & No & \% \\
\hline Calcular obstructive jaundice & 7 & 11 & 18 & 72 \\
\hline Mucoviscidosis & 4 & 2 & 6 & 24 \\
\hline Obstructive jaundice with worm & 1 & 0 & 1 & 4 \\
\hline Failed & 0 & 0 & 0 & 0 \\
\hline Dilated IHBR & 2 & 7 & & \\
\hline \multicolumn{2}{|c|}{ P value } & \multicolumn{4}{|c|}{$<\mathbf{0 . 0 0 1}$ (HS) } \\
\hline
\end{tabular}

As regard the different ERCP procedures done in the two age groups of the studied patients. Clearance of bile ducts from stones (Figure1 and 2) or worm or thick bile using basket forceps and/or the extraction balloon done in all patients $(100 \%)$.

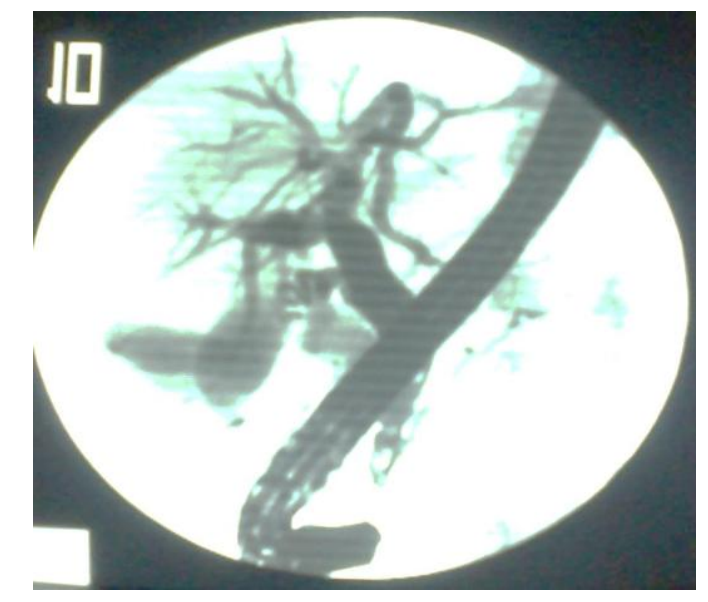

Figure (1): Cholangiography showing multiple filling defects (stones)

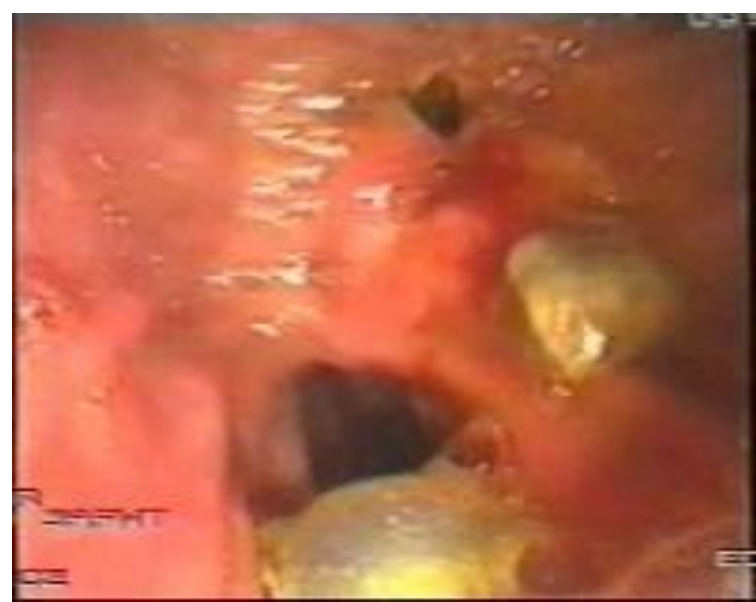

Figure (2): Stone clearance using the extraction balloon 
Endoscopic sphincterotomy (ES) was performed in all patients (Figure 3). Placement of internal biliary prosthesis (stent) was done (Figure 4) in
21 patients $(84 \%)$ [11 patients in group B and 10 patients in group A] (Table 7).

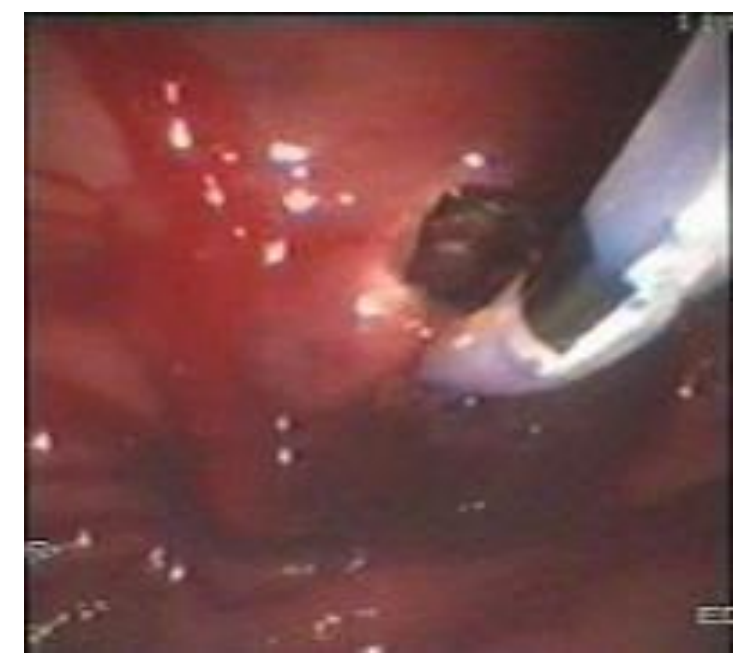

Figure (3): Sphincterotomy of the papilla

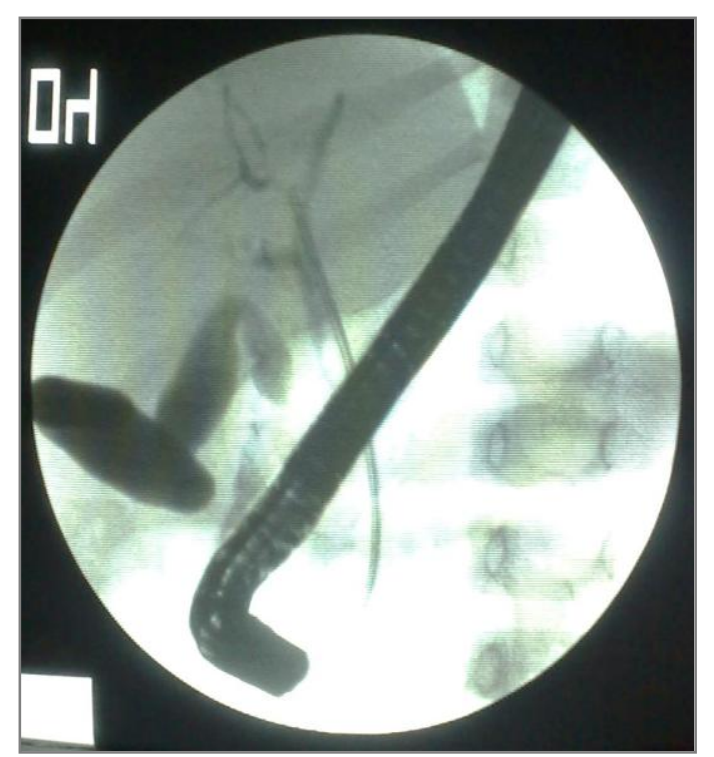

Figure (4): Plastic stent in the common bile duct

Table (7): Therapeutic ERCP procedures done in the studied patients

\begin{tabular}{|l|c|c|c|}
\hline \multirow{2}{*}{ ERCP procedures } & \multicolumn{2}{c|}{ Age group } & \multirow{2}{*}{ Total } \\
\cline { 2 - 3 } & Group A & Group B & \\
\hline Endoscopic sphincterectomy (ES) & 12 & 13 & 25 \\
\hline Clearance of bile duct using basket forceps and/or balloon & 3 & 2 & 5 \\
\hline Stent & 10 & 11 & 21 \\
\hline
\end{tabular}


A total of 17 cases diagnosed with choledocholithiasis were referred to surgical management by laparoscopic cholecystectomy. The one case diagnosed as parasitic worm (Fasciola) improved following ERCP and was treated medically. The cases diagnosed with Mucovicidosis improved following ERCP clearance of the duct and was treated medically (Table 8).

Table (8): Outcome in the age group of studied patients

\begin{tabular}{|l|c|c|c|}
\hline \multicolumn{1}{|c|}{ Outcome } & Group A & Group B & Total \\
\hline Laparoscopic cholecystectomy then stent removal later on & 8 & 9 & 17 \\
\hline Stent removal followed by medical treatment & 2 & 2 & 4 \\
\hline Improved with medical treatment as no stent & 2 & 2 & 4 \\
\hline
\end{tabular}

The rate of ERCP complications encountered in both groups was $12 \%(3 / 25)$. One case had cholangitis following ERCP in group A and one case developed pancreatitis in each group. All cases were treated medically and there was no mortality (Table 9).

Table (9): Complications of ERCP in the studied children

\begin{tabular}{|c|c|c|c|c|c|c|}
\hline \multirow{3}{*}{ Item } & \multicolumn{4}{|c|}{ Age group } & \multirow{2}{*}{\multicolumn{2}{|c|}{ Total }} \\
\hline & \multicolumn{2}{|c|}{$\begin{array}{c}\text { Group A } \\
(\mathrm{n}=12)\end{array}$} & \multicolumn{2}{|c|}{$\begin{array}{c}\begin{array}{c}\text { Group B } \\
(n=13)\end{array} \\
\end{array}$} & & \\
\hline & No & $\%$ & No & $\%$ & No & $\%$ \\
\hline Biliary pancreatitis & 0 & 0 & 1 & 4 & 1 & \\
\hline Cholangitis & 1 & 4 & 1 & 4 & 2 & \\
\hline Death & 0 & 0 & 0 & 0 & 0 & 0 \\
\hline Total & 1 & & 2 & & 3 & \\
\hline
\end{tabular}

\section{DISCUSSION}

Endoscopic retrograde cholangiopancreatography is not as widely used in children as in adults and is performed in few specialized centers. ERCP is an effectual and safe therapeutic procedure in children and adolescents of different ages in a variety of pancreatobiliary disorders [6]. A major advantage of ERCP is that it offers the opportunity to perform endoscopic examination. The cause of the patient's symptoms may be evident on visualization of the papilla of Vater itself. It is reported that ERCP is an established modality for the diagnosis and treatment of pancreatobiliary diseases in adults. Repeated experience with diagnostic and therapeutic ERCP in pediatric patients is limited due to the relatively low incidence of pancreatobiliary diseases, limitations in the size of duodenoscopes, the need for general anesthesia and the lack of highly trained and experienced endoscopists familiar with these special procedures in pediatric patients.

With the refinement of technique and improvement of endoscope design, excellent results have been reported in the pediatric population especially the management of biliary diseases (biliary sphincterotomy to facilitate drainage or stone extraction, stent placement or stricture dilatation) [7]. The incidence of gallstones in children increased in the last years due to both the regular use of the noninvasive detection technique (ultrasonography) and actual increased incidence. ERCP has become a validated diagnostic and therapeutic modality in children with choledocholithiasis, these patients were treated successfully by endoscopic sphincterotomy and stone removal [8-11].

Our study included 25 patients with clinical, laboratory and ultrasound evidence of cholestasis, with calcular biliary obstruction and all had strong suspicion of stone common bile duct. There was no statistical significance when comparing the age groups with the sex of the studied patients. Coinciding with the findings of others in their studies the most common presenting symptoms in all patients was abdominal colic, vomiting, fever and triad of jaundice, dark urine and pale stools (100\%) [6]. Also On clinical examination we noticed that jaundice was the commonest finding in the studied group (100\%). 
Enlarged liver and/or spleen were found in all age groups. These findings were supported by ultrasonographic examination of the abdomen [7].

The different indications for ERCP examination in our study were, confirming the diagnosis of other imaging procedures and temporary relief of obstruction until definitive management was amenable while the most common indications for ERCP in Western children are choledocholithiasis and pancreatitis [8,12]. Indications differ in Asian countries $[11,13,14]$. For example, in Saudi Arabia the most common indication was choledocholithiasis in patients with sickle-cell anemia [11], whereas indication in Japan and India was mostly cholodecal cyst [13-16]. As others demonstrated in recent studies that ERCP was an important diagnostic modality in infants and children of all ages with cholestasis offering valuable detailed information on the biliary and pancreatic ductal system and that it has the advantage over MRCP and CT in offering diagnostic as well as therapeutic capabilities with very minimal insignificant complications $[6,13$, 14,17-19].

The overall success rate in cannulation of the common bile duct and pancreatic duct was $100 \%$ in our study. The higher success rate reported in our study was slightly different than rates reported by many authors $[6,12,18,20,21]$, and this can be explained by the fact that the youngest child in our study was older than 2 years and also the small number of cases in our study is another factor. The stent placement was indicated in 21 of $25(84 \%)$ child; the other 4 children (16\%) just sludges were cleared using basket forceps without the need for stent insertion. Two to three weeks later laparoscopic cholecystectomy was successfully performed to all indicated children with removal of the stent after 2 to three weeks. As reported in other studies, Endoscopic sphincterotomy (ES) and basket extraction of living Fasciola worm from the CBD was performed successfully and without complications in one patient and the children then treated medically $[20,21]$.

In conclusion, the encouraging results of this study with very minimal insignificant complications of ERCP (safety) and good results of ERCP in treatment of CBD stones in children (efficacy) recommend that children with choledocholithiasis due to CBD stone or sludges as (thick bile or worms) should be treated by endoscopic CBD stone or sludges removal to prevent the potential complications of choledocholithiasis which lead to major risks, discomfort, and repeated hospitalization.

Funding:Non.

\section{Conflict of interest:Non.}

Ethical approval: Approved by Ethical Committee of Faculty of Medicine, Zagazig University.

\section{REFERENCES}

1. Bailey PV, Connors RH, Tracy TF Jr, Sotelo-Avila C, Lewis JE, Weber TR. Changing spectrum of cholelithiasis and cholecystitis in infants and children. Am J Surg. 1989; 158 : 585-588.

2. Waldhausen JHT, Benjamin DR. Cholecystectomy is becoming an increasingly common operation in children. Am J Surg. 1999; 177: 364-367.

3. Hsu RK, Draganov P, Leung JW, Tarnasky PR, Yu AS, Hawes RH, et al. Therapeutic ERCP in the management of pancreatitis in children. Gastrointest Endosc. 2000; 51: 396-400

4. Wilkinson MI, Mieli-Vergani O, Ball C, Portmann B, Mowat AP. Endoscopic retrograde cholangiopancreatography in infantile cholestasis. Arch. Dis. Child 1991; 66 : 121-123.

5. Otto AK, Neal MD, Slivka AN, Kane TD. An appraisal of endoscopic retrograde cholangiopancreatography (ERCP) for pancreaticobiliary disease in children: our institutional experience in 231 cases. SurgEndosc. 2011; 23:143-151.

6. Guelrud M. Endoscopic retrograde cholagiopancreatography. Gastrointest Endosc Clin NAm. 2001; 11(4): 585 - 601.

7. Cheng CL, Fogel EL, Sherman S, McHenry L, Watkins JL, Croffie JM, et al. Diagnostic and therapeutic endoscopic retrograde cholangiopancreatography in children: a large series report. J Pediatr Gastroenterol Nutr. 2005; 41: 445-453.

8. Varadarajulu S, Wilcox CM, Hawes RH, Cotton PB. Technical outcomes and complications of ERCP in children. Gastrointest Endosc. 2004; 60: 367-371.

9. Guelrud M, Zambrano V, Jaen D. Endoscopic sphincterotomy and laparoscopic cholecystectomy in a jaundiced infant. Gastrointest Endosc 1994; 40: 99-102.

10. Issa H, Al-Haddad A, Al-Salem AH. Diagnostic and therapeutic ERCP in the pediatric age group. PediatrSurg Int. 2007; 23: 111-116.

11. Pfau PR, Chelimsky GG, Kinnard MF, Sivak MV Jr, Wong RC, Isenberg GA, et al. Endoscopic retrograde cholangiopancreatography in children and adolescents. J Pediatr Gastroenterol Nutr 2002; 35: 619-623. 
12. Poddar U, Thapa BR, Bhasin DK, Prasad A, Nagi B, Singh K. Endoscopic retrograde cholangiopancreatography in the management of pancreaticobiliary disorders in children. $J$ Gastroenterol Hepatol. 2001; 16: 927-993.

13. Keil R, Snajdauf J, Stuj J, Kalousova J, Nevolova P, Janik V, et al. Endoscopic retrograde cholangiopancreatography in infants and children. Indian J Gastroenterol. 2000; 19(4): 175 - 177.

14. Poddar U, Thapa BR, Chhabra M, Rao KL, Mitra SK, Dilawari JB, et al. Choledochal cysts in infants and children. Indian Pediatr. 1998; 35 (7):613-618.

15. Kumar R, Nguyen K, Shun A. Gallstones and common bile duct calculi in infancy and childhood. Aust N Z J Surg. 2000; 70(3):188-191.

16. Ohnuma N, Takahashi T, Tanabe M, Yoshida H, Iwai J. The role of ERCP in biliary atresia. Gastrointest. Endosc 1997;45 (5): 365 - 370.

17. Taj MA, Leghari A, Qureshi S, Ghazanfar S, Niaz SK, Quraishy MS. Endoscopic retrograde cholangiopancreatography: a therapeutic modality in children and adolescents.J Pak Med Assoc. 2012; 62(2):98-101.
18. De Angelis P, Foschia F, Romeo E, Caldaro T, Rea F, di Abriola GF, et al. Role of endoscopic retrograde cholangiopancreatography in diagnosis and management of congenital choledochal cysts: 28 pediatric cases. Pediatr Surg. 2012; 47(5): 885-888.

19. Davenport M, Betalli P, D'Antiga L, Cheeseman P, Mieli-Vergani G, Howard, ER. The spectrum of surgical jaundice in infancy. Journal of Pediatr Surg. 2003; 38(10): 1471-1479.

20. Reddy DN, Sriram PV, Rao GV. Endoscopic diagnosis and management of tropical parasitic infestations. Gastrointest Endosc Clin $N$ Am. 2003; 13(4): $765-773$

21. Ozer B, Serin E, Gumurdulu Y, Gur G, Yilmaz U, Boyacioglu S. Endoscopic extraction of living fasciola hepatica: case report. Turk J Gastroenterol. 2003; 14(1): 74-77.

Peer Reviewer: Mohamad M. Radwan: Assistant professor of Tropical Medicine and Hepatogastroenterology ,Faculty of Medicine ,Zagazig Universty,Egypt.

Editor:Mohamad Emara:Lecturer of Tropical Medicine and Hepatogastroenterology ,Faculty of Medicine ,Zagazig Universty ,Egypt. 